\title{
Neuropsychology
}

\section{Topological Map of the Body in Post-Stroke Patients: Lesional and Hodological Aspects}

Antonella Di Vita, Liana Palermo, Maddalena Boccia, and Cecilia Guariglia

Online First Publication, February 7, 2019. http://dx.doi.org/10.1037/neu0000536

CITATION

Di Vita, A., Palermo, L., Boccia, M., \& Guariglia, C. (2019, February 7). Topological Map of the Body in Post-Stroke Patients: Lesional and Hodological Aspects. Neuropsychology. Advance online publication. http://dx.doi.org/10.1037/neu0000536 


\title{
Topological Map of the Body in Post-Stroke Patients: Lesional and Hodological Aspects
}

\author{
Antonella Di Vita \\ "Sapienza" University of Rome and I.R.C.C.S. Santa Lucia \\ Foundation, Rome, Italy \\ Maddalena Boccia \\ I.R.C.C.S. Santa Lucia Foundation, Rome, Italy
}

\author{
Liana Palermo \\ Magna Graecia University of Catanzaro and I.R.C.C.S. Santa \\ Lucia Foundation, Rome, Italy \\ Cecilia Guariglia \\ "Sapienza" University of Rome and I.R.C.C.S. Santa Lucia \\ Foundation, Rome, Italy
}

\begin{abstract}
Objective: It has been repeatedly hypothesized that at least 3 distinct types of body representations do exist: body schema, a representation derived from multiple sensory and motor inputs; topological map of the body, a structural description of spatial relations among the body parts; and body semantics, a lexical-semantic representation. Although several studies have assessed neural correlates of the topological map of the body in healthy participants, a systematic investigation of neural underpinnings of the topological map of the body in brain-damaged patients is still lacking. Method: Here we investigated the neural substrates of topological map of the body in 23 brain-damaged patients, both from a topological and an hodological perspectives, using Voxel Lesion Symptom Mapping and atlas-based track-wise statistical analysis. Besides neuroimaging investigation, consisting of T1-weighted and FLAIR sequences, patients underwent the frontal body-evocation subtest (FBE) to assess the topological map of the body. Results: The present results reveal a large-scale brain network involved in the topological map of the body assessed with FBE, encompassing both regions of primary elaboration and multisensory associative areas, in the temporal, parietal, frontal, and insular cortices. Hodological analysis revealed significant association between processing of the body topological map and the disconnection of the frontomarginal tract. Conclusions: These findings suggest that the topological map of the body is built up basing on both external and internal information that comes from the body and are constantly updated and integrated. The theoretical and clinical relevance of these results is discussed.
\end{abstract}

\section{General Scientific Summary}

The present study investigates the neural underpinnings of body representation in stroke patients. Both the topological and hodological approaches show that the knowledge about the spatial features of the body is based on the processing of different bodily information and their multisensory integration. Considering that a deficit in the topological map of the body was identified in patients affected by personal neglect, understanding the nature of such representation could be helpful in better define the clinical features of personal neglect and in designing possible rehabilitation trainings.

Keywords: body representation, topological map of the body, body schema, VLSM

The body is the central tool of human mind (Knoblich, Thorton, Grosjean, \& Shiffrar, 2006) and allows us to interact with the external world: indeed, through our own body we act in the world, communicate intentions, feelings and moods, receive and process information, and so forth. The importance of the body in disclosing and defining our identity becomes clear when looking at its central role in different cultural expressions. From literature to philosophy and painting, the body is a key object of the creative and cultural
Antonella Di Vita, Department of Psychology, "Sapienza" University of Rome, and Cognitive and Motor Rehabilitation and Neuroimaging Unit, I.R.C.C.S. Santa Lucia Foundation, Rome, Italy; Liana Palermo, Department of Medical and Surgical Sciences, Magna Graecia University of Catanzaro, and Cognitive and Motor Rehabilitation and Neuroimaging Unit, I.R.C.C.S. Santa Lucia Foundation; Maddalena Boccia, Cognitive and Motor Rehabilitation and Neuroimaging Unit, I.R.C.C.S. Santa Lucia Foundation; Cecilia Guariglia, Department of Psychology, "Sapienza" University of Rome, and Cognitive and Motor Rehabilitation and Neuroimaging Unit, I.R.C.C.S. Santa Lucia Foundation.

Correspondence concerning this article should be addressed to Antonella Di Vita, via dei Marsi 78, 00185, Rome, Italy. E-mail: antonella.divita@ uniroma1.it 
expression of nearly all cultures, since the beginning of civilization.

From a neuroscientific point of view, the body represents a unique object of investigation, being the only one we can explore from an internal point of view. This has led neuroscientists to increasingly focus on studying how the brain processes the body (Carruthers, 2008). A triadic taxonomy has been developed that identifies three distinct types of body representations: (a) a verbally coded knowledge, that is, a semantic and lexical representation of the body, involved in naming body parts and in recognizing their specific functions; (b) a visuospatial representation (hereafter called topological map of the body) that processes location and spatial features of single body parts, as well as their boundaries and reciprocal spatial relations; and (c) a dynamic representation of the body (body schema), that guides actions on the basis of sensorimotor afferent and efferent information of the body (Schwoebel \& Coslett, 2005; Sirigu, Grafman, Bressler, \& Sunderland, 1991). Longo (2016) provided an overview of previous studies on different body representations according to two main dimensions, namely the perceptual versus conceptual and the explicit versus implicit dimensions. In this framework, six body representations were identified: (a) the body image, which processes the conscious experience of the size, the shape, and the other physical proprieties of our bodies; (b) the body schema, which mainly overlaps with previous definitions of body schema (see Head, 1920); (c) the superficial schema, which mediates the localization of stimuli on the body surface; (d) the body model, which encompasses the metric properties of the body underlying perception; (e) the body semantic, which conveys abstract knowledge of the body; and (f) the body structural description, which consists of a spatial representation of the body parts relative to each other.

Terms like body structural description and body structural representation have been used to refer to the conceptual, implicit representations of the body. Our previous studies demonstrated that the spatial relation between body parts is not completely hard-wired in the brain, but it develops as a consequence of the actual interaction with our own body and may be affected by peripheral and central lesions (Palermo, Di Vita, Piccardi, Traballesi, \& Guariglia, 2014). In this vein, tasks tapping on the spatial relation between body parts require the interaction between the higher-level percepts, defined by Longo and colleagues (2010) "somatoperception," and the abstract knowledge about one's own body, defined by Longo and colleagues (2010) "somatorepresentation." Here we will use "topological map of the body" to indicate the representation involved in tasks tapping on the spatial relations among body parts, and that is based on the interaction between somatoperception and somatorepresentation.

Neuroimaging studies on healthy individuals, using different methodologies (i.e., functional magnetic resonance imaging, transcranial magnetic stimulation, transcranial direct current stimulation), have demonstrated a pivotal role of the parietal cortex in processing the spatial relations among body parts (CorradiDell'Acqua, Acqua Hesse, Rumiati, \& Fink, 2008; CorradiDell'Acqua, Tomasino, \& Fink, 2009; Ehrsson, Kito, Sadato, Passingham, \& Naito, 2005; Felician et al., 2004; Le Clec'H et al., 2000; Spitoni et al., 2013; Urgesi, Calvo-Merino, Haggard, \& Aglioti, 2007). Hodzic, Kaas, Muckli, Stirn, and Singer (2009) found that right fronto-parietal connections subserve the visual processing of both one's own body and others' body. Several studies agree with the fact that such a process shows cerebral lateralization, however, results are inconsistent in terms of where in the brain it is lateralized: Spitoni and coworkers (Spitoni, Galati, Antonucci, Haggard, and Pizzamiglio (2010; Spitoni et al., 2013) and Urgesi et al. (2007) found that the right angular gyrus and the superior parietal lobe were involved in processing the spatial relationships among body parts, whereas Corradi-Dell'Acqua and coworkers (2008, 2009); Ehrsson et al. (2005), and Felician et al. (2004) found that this process engaged left postcentral sulcus, the anterior part of the intraparietal sulcus and left superior parietal lobe. Unresolved lateralization of the network subserving the nonaction oriented body representation (NA), that includes also the topological map of the body, emerges also in a recent metaanalysis of fMRI studies (Di Vita, Boccia, Palermo, \& Guariglia, 2016). Interestingly, Berlucchi and Aglioti (2010), in reviewing studies about the role of the extrastriate body area (EBA), noticed that the right EBA is more active than the left one in processing the body, and that the laterality of body selective areas is still poorly investigated.

Findings in healthy individuals are consistent with evidence coming from neuropsychological investigations in brain damaged patients, which also shed some light upon unresolved question about lateralization. For example, a deficit in representing relations among body parts-namely, autotopoagnosia-is generally associated with lesions of the parietal lobe in the left hemisphere (Denes, 1989; Guariglia, Piccardi, Puglisi Allegra, \& Traballesi, 2002). Schwoebel and Coslett (2005) found that deficits in the visuospatial body map were more frequent after a left temporal lesion. However, evidence about deficits in processing spatial knowledge of the body following damage of the right hemisphere suggests that also the right hemisphere plays a crucial role in topological map of the body. Specifically, patients with personal neglect, a neuropsychological disorder usually resulting from lesions within the right hemisphere, show deficit in tasks tapping the topological map of the body (Di Vita et al., 2017; Palermo et al., 2014).

Notwithstanding many studies have investigated its neural underpinnings in healthy individuals, a systematic investigation of brain networks involved in deficit of topological map of the body is still lacking. Here we fill this gap investigating the neural underpinnings of topological map of the body in focal braindamaged patients, with the aim of providing a systematic picture of the brain areas causally engaged in this kind of representation. To this aim, we performed a topological and an hodological anatomoclinical correlation study on left and right brain-damaged patients, directly investigating topological map of the body by using frontal body-evocation subtest (FBE) of the body representation test.

\section{Materials and Methods}

\section{Participants}

After obtaining their informed consent, 23 brain-damaged patients with unilateral stroke were enrolled in the study. The patient group included seven patients with left brain damage (LP; $M$ age $=60.57, S D=7.48 ; M$ education $=9.43, S D=4.50)$, and 16 patients with right brain damage; right brain-damaged patients were further divided according to presence (right brain damaged patients with personal neglect, $\mathrm{RPN}+=7 ; M$ age $=66.86, S D=$ 
10.62; $M$ education $=9.57, S D=5.02$ ) or the absence of personal neglect (right brain damaged patients without personal neglect, RPN- $=9 ; M$ age $=60.33, S D=20.52 ; M$ education $=10.67$, $S D=5.38$ ); criteria for this further division are specified below.

A group of nine healthy controls with no history of neurologic or psychiatric diseases, or general cognitive impairment (see below), matched for age and education with those of patients $(\mathrm{C} ; M$ age $=63.22, S D=11.61 ; M$ education $=12.33, S D=5.17)$ was also included. One-way analyses of variance (ANOVAs) on age $\left(F_{3,28}=0.351 ; p=.789\right)$ and education $\left(F_{3,28}=0.572 ; p=.638\right)$ did not reveal differences among the groups. The study was approved by the local ethics committee and was carried out according to the principles of the Helsinki Declaration.

\section{Behavioral Testing: General neuropsychological Assessment}

All patients underwent a neuropsychological examination that included an assessment of abstract and/or verbal reasoning (Raven's colored progressive matrices-Basso, Capitani, \& Laiacona, 1987; Raven, 1938; or Spinnler \& Tognoni, 1987), to exclude patients affected by deficits in abstract reasoning abilities and/or cognitive deterioration. Language comprehension skills were extensively assessed in left-brain-damaged patients by an expert clinical neuropsychologist through a variety of tests that required a word and a sentence-level auditory comprehension: Token test (Spinnler \& Tognoni, 1987), the comprehension subtests of "Esame del Linguaggio" (Ciurli, Marangolo, \& Basso, 1996) and "Batteria per l'Analisi dei Deficit Afasici" (Miceli, Laudanna, Burani, \& Capasso, 1994). The presence of visuospatial neglect was assessed by means of the Standard Battery for the Evaluation of Hemineglect (Pizzamiglio, Judica, Razzano, \& Zoccolotti, 1989), which includes four tests: Letter Cancellation, Line Cancellation, Wundt-Jastrow Area Illusion, and Sentence Reading. Patients who performed below the cut-off on at least two of the four tests were classified as presenting extrapersonal neglect. Personal neglect was assessed by means of the Use of Common Objects test (Zoccolotti, Antonucci, \& Judica, 1992) and results were used to divide the group of right brain damaged patients in two subgroups, according to the presence/absence of personal neglect. See Table 1 for patients' demographic and assessment data.

All control participants performed well-within the normal range in tests assessing global cognitive functioning (Mini-Mental State Examination, Magni, Binetti, Bianchetti, Rozzini, \& Trabucchi, 1996; Milan Overall Dementia Assessment, Brazzelli, Capitani, Della Sala, Spinnler, \& Zuffi, 1994).

\section{Behavioral Testing: Topological Map of the Body}

The topological map of the body was assessed by using the FBE of the Body Representation Test (Daurat-Hmeljiak Stambak \& Berges, 1978). This test has been extensively used to assess body representation deficits in adults with brain-damages (e.g., Di Vita, Palermo, Piccardi, \& Guariglia, 2015, 2017; Guariglia \& Antonucci, 1992; Guariglia et al., 2002; Palermo et al., 2014) or with lower-limb amputations (Palermo et al., 2014).

Test materials included a plastic board on which the position of the head was depicted as reference, and nine tiles, each representing a body part (see Figure 1). Participants were presented with one tile at a time. The task was to identify the body part depicted

Table 1

Demographic and Assessment Data of Stroke Patients

\begin{tabular}{|c|c|c|c|c|c|c|}
\hline Participants & Group & Gender & $\begin{array}{l}\text { Time since } \\
\text { stroke (days) }\end{array}$ & $\begin{array}{c}\text { Abstract or } \\
\text { verbal reasoning }\end{array}$ & Token test & $\begin{array}{l}\text { Standard Battery for } \\
\text { the Evaluation of Hemineglect }\end{array}$ \\
\hline Pt1 & LP & $\mathrm{m}$ & 50 & $25 / 36 \mathrm{R}$ & $33 / 36$ & + \\
\hline Pt2 & LP & $\mathrm{m}$ & 28 & $30 / 36 \mathrm{R}$ & $35 / 36$ & + \\
\hline Pt3 & LP & $\mathrm{m}$ & 26 & $28 / 36 \mathrm{R}$ & 35736 & + \\
\hline Pt4 & LP & $\mathrm{m}$ & 62 & $28 / 36 \mathrm{R}$ & $24 / 36$ & + \\
\hline Pt5 & LP & $\mathrm{f}$ & 57 & $27 / 36 R$ & $29 / 36$ & + \\
\hline Pt6 & LP & $\mathrm{m}$ & 39 & $19 / 36 \mathrm{R}$ & $30 / 36$ & + \\
\hline Pt7 & LP & $\mathrm{m}$ & 23 & $31 / 36 \mathrm{R}$ & $30 / 36$ & + \\
\hline Pt8 & RPN- & $\mathrm{f}$ & 22 & $24 / 36 \mathrm{R}$ & & + \\
\hline Pt9 & RPN- & $\mathrm{m}$ & 32 & $32 / 36 \mathrm{R}$ & & + \\
\hline Pt10 & RPN- & $\mathrm{m}$ & 31 & $32 / 36 \mathrm{R}$ & & + \\
\hline Pt11 & RPN- & $\mathrm{f}$ & 31 & $29 / 36 \mathrm{R}$ & & + \\
\hline Pt12 & RPN- & $\mathrm{m}$ & 30 & $35 / 36 \mathrm{R}$ & & + \\
\hline Pt13 & RPN- & $\mathrm{m}$ & 28 & $28 / 36 \mathrm{R}$ & & + \\
\hline Pt14 & RPN- & $\mathrm{f}$ & 28 & $17 / 36 \mathrm{R}$ & & + \\
\hline Pt15 & RPN- & $\mathrm{m}$ & 89 & $23 / 36 \mathrm{R}$ & & - \\
\hline Pt16 & RPN- & f & 14 & $28 / 36 \mathrm{R}$ & & + \\
\hline Pt17 & $\mathrm{RPN}+$ & $\mathrm{f}$ & 33 & $26 / 36 R$ & & + \\
\hline Pt18 & RPN+ & $\mathrm{m}$ & 68 & $28 / 36 \mathrm{R}$ & & + \\
\hline Pt19 & RPN+ & f & 66 & 18/36 R & & - \\
\hline Pt20 & $\mathrm{RPN}+$ & $\mathrm{f}$ & 78 & $46 / 60 \mathrm{VJ}$ & & - \\
\hline Pt21 & RPN+ & $\mathrm{m}$ & 39 & $17 / 36 \mathrm{R}$ & & - \\
\hline Pt22 & RPN+ & $\mathrm{m}$ & 147 & $36 / 60 \mathrm{VJ}$ & & - \\
\hline $\mathrm{Pt} 23$ & $\mathrm{RPN}+$ & $\mathrm{m}$ & 30 & $46 / 60 \mathrm{VJ}$ & & - \\
\hline
\end{tabular}

Note. $\quad \mathrm{RNP}-=$ right brain damaged patients without personal neglect; $\mathrm{RNP}+=$ right brain damaged patients with personal neglect; $\mathrm{LP}=$ left brain damaged patients; R = Raven's Colored Progressive Matrices (Basso, Capitani, \& Laiacona, 1987); VJ = Verbal Judgement Test (Spinnler \& Tognoni, 1987) 


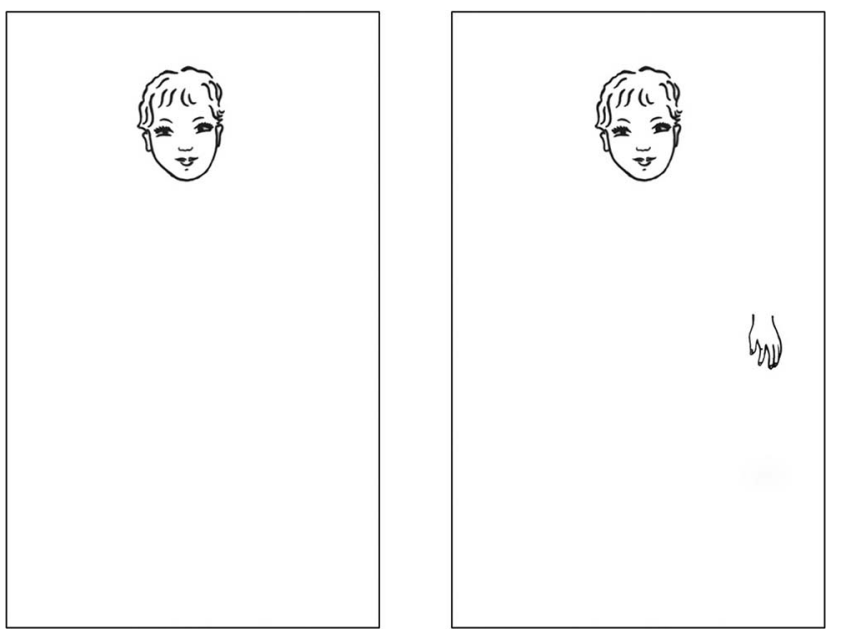

Figure 1. Frontal body-evocation subtest (Daurat-Hmeljiak et al., 1978) for the assessment of the topological map of the body. On the left panel, the starting configuration is provided. An example of tile positioning is provided on the right panel.

on the tile by naming it and then to place it on the board. The position of the tile was recorded by overlapping a transparent grid, which is removed together with the tile before presenting the next tile. The number of correct answers was recorded (max score 9).

\section{Behavioral Testing: Data Analysis}

Statistical analyses were performed using SPSS (IBM SPSS Statistics 20). A one-way ANOVA with the Group (C vs. LP vs. $\mathrm{RPN}+$ vs. RPN-) as independent variable and the number of correct responses at FBE as dependent variable was used to test differences between groups on topological map of the body.

Considering that there was a strong overlap between patients affected by personal neglect and patients affected by visuospatial neglect (only two patients were affected by pure personal neglect) we also performed a $2 \times 4$ mixed-factorial ANOVA, with the number of left body parts erroneously placed to the right (i.e., left-right inversion; LRI) and the number of right body parts erroneously placed to the left (i.e., right-left inversion; RLI) as within-subject factor and the Group (C vs. LP vs. RPN + vs. RPN-) as between-subjects factor.

Post hoc pairwise comparisons in all the analyses were performed using $t$ tests and Bonferroni's correction for multiple comparisons, as implemented in SPSS.

\section{Neuroimaging Investigation: Neuroimaging Acquisition and Lesion Analyses}

An in-depth MRI evaluation using a 3T Allegra scanner (Siemens Medical Systems, Erlangen, Germany) was carried out for 23 patients, within 3 days from the experimental assessment of the topological map of the body. In order to maximize both sensitivity and tissue specificity, and to obtain an accurate characterization of the pathological tissue in vivo, different anatomical sequences were combined, including a dedicated high-resolution T1weighted image (MDEFT: Siemens MDEFT, 176 slices, in-plane resolution $=1 \times 1 \mathrm{~mm}$, slice thickness $=1 \mathrm{~mm}, \mathrm{TR}=7.92 \mathrm{~s}$, $\mathrm{TE}=2.4 \mathrm{~s})$ of the whole brain and fluid attenuated inversion recovery image (FLAIR: 24 slices, $192 \times 256$ matrix, slice thickness $=5.5 \mathrm{~mm}$, TE $=109 \mathrm{~ms}, \mathrm{TR}=8.17 \mathrm{~s})$.

Lesions were manually drawn on each patient's T1-weighted scans in the subject space (i.e., with a resolution below $1 \mathrm{~mm}$ ), using the MRIcron software, and then resampled to MNI152 space using normalization parameters estimated by the SPM8 (Wellcome Department of Cognitive Neurology, London, UK) and, restricting the estimation of the normalization parameters to the healthy tissue, by means of lesion masking (Brett, Leff, Rorden, \& Ashburner, 2001).

Neuroimaging investigation: Topological lesion-deficit analysis. A voxel lesion symptom mapping (VLSM) analysis (Bates et al., 2003) was performed by means of the NonParametric Mapping software (Rorden, Karnath, \& Bonilha, 2007). For each voxel, VLSM analysis splits the sample between patients with and without lesions in that voxel and compares the behavioral scores of lesioned and nonlesioned patients using the Brunner and Munzel rank-order statistical test for continuous measures, testing for significant difference on a voxel-by-voxel basis (Bates et al., 2003). Thus, going beyond the simple group's division according to a dichotomous criterion (i.e., presenceabsence of a given symptom), this analysis allows for testing more fine-graded symptom-lesion association. Here, behavioral scores, namely Patients' scores on FBE (Daurat-Hmeljiak et al., 1978), were entered in the VLSM analysis, which was performed using 2000 permutations. Multiple comparisons issue was accounted by false discovery rate correction $(p<.01)$.

Neuroimaging investigation: Hodological lesion-deficit analysis. Tractotron, as part of the BCB toolkit (http://www .brainconnectivitybehavior.eu/), was used to identify the tracts that could be affected by individual patient's lesion. Tractotron automatically computes the overlap of each segmented lesion with the map of the tracts.

Lesion from each patient was mapped onto the tractography reconstructions of white matter pathways obtained from a group of healthy controls (Rojkova et al., 2016). The severity of the disconnection was quantified by measuring the probability of the tract to be disconnected (Thiebaut De Schotten et al., 2014). A tract was considered disconnected when a lesion overlapped with a voxel that belonged to this tract with a probability that was above the chance level (probability $>0.5$ ). In the light of the analysis pipeline on track-wise statistics (see below), which mainly consisted of correlation and regression analyses, only tracts disconnected in at least $10 \%$ of patient entered further analyses.

A Pearson correlation analysis was carried out to identify tracts whose disconnection was associated with the performance at FBE. Then, a linear regression analysis was performed by using the patients' scores on FBE as the dependent variable, and lesion size and the probability of disconnections of the tracts-individuated troughs the correlation analysis - as the independent variables.

\section{Results}

\section{Behavioral Data}

The one-way ANOVA with the group as independent variable and FBE performance as dependent variable revealed a main effect of the group $\left(\mathrm{F}_{3,28}=6.513 ; p=.002 ; \eta_{p}^{2}=0.411 ;\right.$ observed 
power $=0.947)$. Post hoc pairwise comparisons showed that $\mathrm{RPN}+$ (mean FBE's score $=3.86 ; S D=1.57$ ) significantly differs from $C(p=.001$; mean FBE's score $=7.00 ; S D=1.32)$, $\mathrm{LP}(p=.038$; mean FBE's score $=6.14 ; S D=0.90)$ and RNP$(p=.027$; mean FBE's score $=6.11 ; S D=1.76)$. No other differences among groups were detected (all $\mathrm{p}_{\mathrm{s}}=1.00$ ).

The $2 \times 4$ mixed-factorial ANOVA, with the number of LRI and RLI errors as within-subject factor and group as betweensubjects factor revealed a main effect of the group, $F_{(3,28)}=$ 4.019; $p=.017 ; \eta_{p}^{2}=0.301$ (observed power $=0.782$ ), but it failed in finding significant effect of type of error, $F_{(1,28)}=0.212$, $p=.649 ; \eta_{p}^{2}=0.008$ (observed power $=0.073$ ); the Type of Error $\times$ Group interaction did not reach the statistical significance, $F_{(3,28)}=0.023, p=.995 ; \eta_{p}^{2}=0.002$ (observed power $=0.053$ ). The RPN + performed significantly worse than C $(p=.020)$, suggesting that their worse performance on FBE are not due to LRI or RLI (see Table 2 for mean and standard deviation of LRI and RLI errors in each group). No other differences among groups were detected (all $p_{\mathrm{s}}>0.06$ ).

\section{Neuroimaging Data}

Topological lesion-deficit analysis. The VLSM analysis (see Figure 2) showed that low scores on FBE test were significantly associated with lesions in clusters of voxels in the right hemisphere, which were mainly located in the putamen, the anterior insula, temporal (i.e., middle and superior temporal gyrus extending to the temporo-parietal junction [TPJ]), parietal (i.e., postcentral gyrus; angular gyrus, and supramarginal gyrus) and frontal lobes (i.e., middle and inferior frontal gyri as well as precentral gyrus), extending to the surrounding white matter.

Hodological lesion-deficit analysis. The correlation analysis revealed that the probability of disconnection of the right cingulum $(\mathrm{r}=-0.393 ; p=.032)$, fronto marginal tract $(\mathrm{r}=-0.481 ; p=$ $.010)$, Handmid_U tract $(\mathrm{r}=-0.363 ; p=.045)$, Handsup_U tract $(\mathrm{r}=-0.399 ; p=.030)$, inferior longitudinal $(\mathrm{r}=-0.368 ; p=$ $.042)$ andoptic radiations $(\mathrm{r}=-0.389 ; p=.033)$ were significantly negatively associated to the FBE's scores.

As it has been mentioned above, the probability of tracts disconnection, obtained from correlation analysis, was subsequently used in the regression analysis, with lesion size as independent

Table 2

LRI and RLI Errors

\begin{tabular}{lrr}
\hline \multicolumn{1}{c}{ Error } & $M$ & $S D$ \\
\hline LRI & & \\
C & .11 & .333 \\
RNP- & .22 & .441 \\
RNP+ & .86 & 1.464 \\
LP & .29 & .488 \\
RLI & & \\
C & .22 & .441 \\
RNP- & .33 & .707 \\
RNP+ & 1.00 & 1.000 \\
LP & .29 & .488 \\
\hline
\end{tabular}

Note. $\quad$ LRI $=$ left-right inversion errors; RLI $=$ right-left inversion errors; $\mathrm{C}=$ controls; $\mathrm{RNP}-=$ right brain damaged patients without personal neglect; $\mathrm{RNP}+=$ right brain damaged patients with personal neglect; $\mathrm{LP}=$ left brain damaged patients.
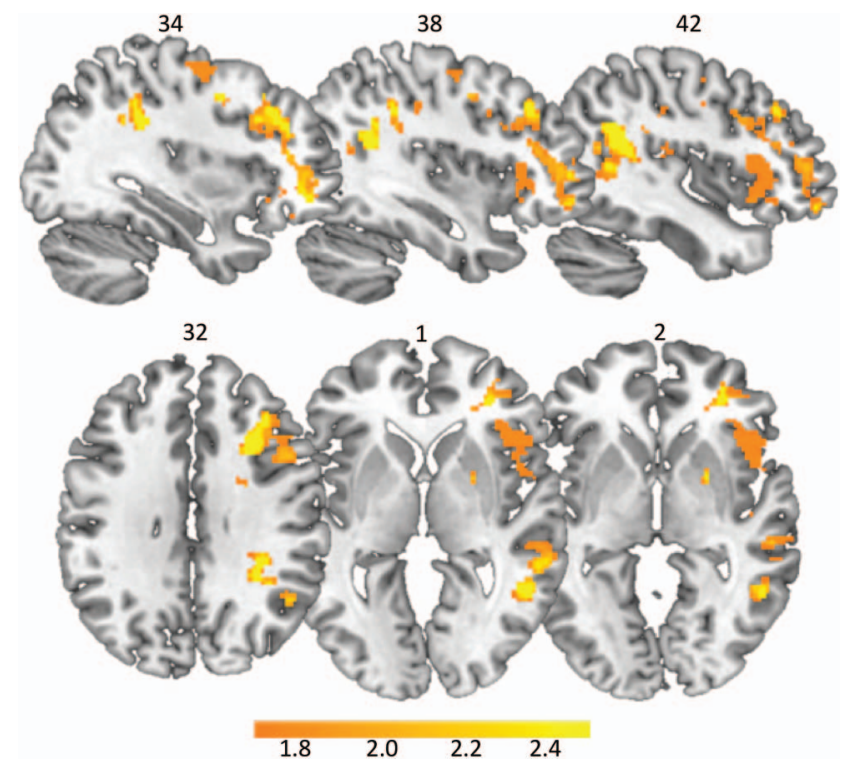

Figure 2. The map shows the $\mathrm{Z}$ statistic, corresponding to the Brunner and Munzel rank-order statistic, comparing the frontal body-evocation subtest's performance between patients with and without lesions in any voxel (central row), on sagittal (top panel) and axial (bottom panel) planes. Lower threshold (1.70) was chosen to be equal to FDR (false discovery rate) corrected $p=.05$, so that only voxels surviving this threshold are showed. See the online article for the color version of this figure.

variables and FBE's performance as dependent variable. This analysis revealed that only the disconnection of the frontomarginal tract in the right hemisphere $(\beta=-0.481 ; p=.020)$ significantly predicted FBE's performances (see Figure 3 ).

\section{Discussion}

The aim of the present study was to provide a detailed picture of the neural substrates of the topological map of the body in braindamaged patients. Using a data-driven correlational analysis

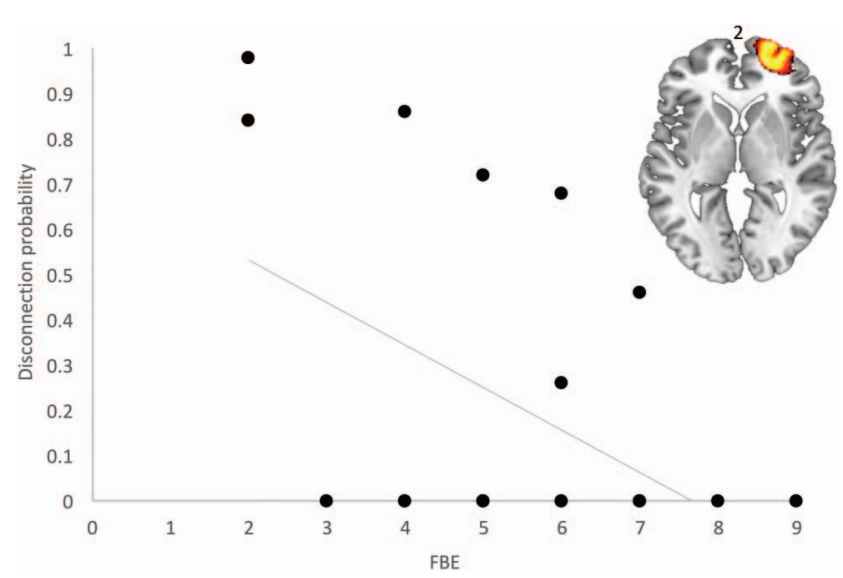

Figure 3. Scatter plot shows the correlation between frontal bodyevocation subtest (FBE) scores and disconnection probability of the right fronto marginal $U$ tract, depicted in the top of the panel on axial plan. See the online article for the color version of this figure. 
(VLSM analysis), we found that worse performances on a test tapping the topological map of the body were associated with lesions in the right hemisphere, involving putamen, anterior insula, temporal (i.e., middle and superior temporal gyrus extending to the TPJ), parietal (i.e., postcentral gyrus; angular gyrus, and supramarginal gyrus) and frontal lobe (i.e., middle and inferior frontal gyri as well as precentral gyrus), extending to the surrounding white matter.

Behavioral data showed that patients affected by personal neglect made a significantly higher number of errors compared to controls in a test that requires individuals to place different body parts in a coherent topological representation, that is a task requiring the generation of the mental image of the body.

The impaired performances we observed in patients with personal neglect do not seem to be due to the presence of visuospatial neglect. Although the majority of the patients with personal neglect also showed visuospatial neglect, did not show any lateral asymmetry (i.e., more errors for the left items than for the right ones); furthermore, also the number of inversion errors (which could be due to exploratory asymmetries) in the group of patients with personal neglect did not significantly differ form that observed in the other groups of patients, who were not affected by any spatial or explorative disorder. Generally, the present results confirm previous behavioral data suggesting the presence of specific body representations deficits in personal neglect (Baas et al., 2011; Coslett, 1998; Di Vita, Palermo, Piccardi, Di Tella, Propato, \& Guariglia, 2017; Palermo et al., 2014).

Taken together with data by Committeri et al. (2007), who showed the involvement of the inferior parietal lobe in personal neglect, present results strongly support the hypothesis that personal neglect is due to a body representation deficit. This is also consistent with studies in which personal neglect has been found to be related to a disconnection between regions encoding proprioceptive/somatosensory inputs and regions encoding a more abstract and egocentric representation of the body space, such as the supramarginal gyrus (Coslett, 1998; Galati, Committeri, Sanes, \& Pizzamiglio, 2001).

The involvement of the right anterior insula, we found here, is consistent with the model outlined by Dijkerman and de Haan (2007), who proposed that the insula provides the neural substrates for perception and memory of body sensations, and with the hypothesis that the inputs needed to form body representations are not exclusively exteroceptive but also interoceptive. Consistently, the anterior insula has been associated with processing of pain, temperature, itching, muscular and visceral sensations, hunger, and thirst (Craig, 2003; Grossi et al., 2014). Present findings demonstrating the involvement of the postcentral gyrus and insula strongly suggest the hypothesis that to properly reconstruct a topological map of the body, a mental image of the body must be generated, starting from both esteroceptive and interoceptive information.

The TPJ seems to be essential in generating this mental image, because it is involved in building an internal model of the body that operates as a stored model for comparing new stimuli (Tsakiris, Costantini, \& Haggard, 2008). According to Tsakiris and colleagues (2008), stimuli are processed and compared with an abstract model of the body, that maintains a coherent sense of the body. The model includes a body description based on visual information and information about the body's anatomical and structural properties (Costantini \& Haggard, 2007; Tsakiris \& Haggard, 2005). Arzy, Thut, Mohr, Michel, and Blanke (2006) also found that the TPJ is specifically involved in self processing and multisensory integration of body-related information; indeed, TPJ resulted involved when participants had to generate a mental image of their own body in a disembodied self-location, but not when they had to generate a mental body image in an embodied position.

The involvement of TPJ, insula, and postcentral gyrus, therefore, suggests that to reconstruct a topological body map, individuals need to access to their own body image which provide a more schematic and abstract representation. This would support the idea that different pieces of information, other than the visual ones (that may come also from bodies of other individuals), are necessary. These results are in line with those by Palermo et al. (2014) on brain-damaged and amputee patients, showing that this type of body representation is not completely hard-wired in the brain. Instead, it seems to develop as a consequence of the actual interaction with our own body, and to not exclusively rely on visual information, as it was previously hypothesized (Schwoebel \& Coslett, 2005; Tessari, Ottoboni, Baroni, Symes, \& Nicoletti, 2012) and demonstrated using fMRI (Rusconi et al., 2014).

Present data are also largely consistent with those by Anema et al. (2008), who demonstrated the involvement of angular gyrus in patients with alterations of the knowledge about the normal configuration of body parts. Similarly, Spitoni and colleagues (2013, 2010) argued for a crucial role of the angular gyrus in processing the metric components of body representation.

The involvement of supramarginal gyrus is in line with previous results (Di Vita et al., 2016) showing that nonaction oriented body representation selectively activates the primary somatosensory cortex and the supramarginal gyrus.

The involvement of the precentral cortex, a motor area, seems to contradict the nonoriented to action nature of the topological body map. Nonetheless, the role of the precentral cortex may be explained by the general role of this area in representing, at an abstract level, body configurations necessary to motor actions (Le Clec'H et al., 2000). This interpretation is supported by a recent study on healthy individuals which demonstrated the dynamic adaptation of visuospatial body map/structural body representation as a function of the postural changes (Tamè, Dransfield, Quettier, \& Longo, 2017). It is also consistent with findings showing that the pre/postcentral gyri underpin visuospatial mental imagery independently from motor intentions (Boccia et al., 2015). Thus, considering the imaginative nature of FBE task, the association between FBE's performance and lesions of prepost central gyrus is not surprising.

With regards to the right middle temporal gyrus, to the best of our knowledge, no studies on body processes have specifically considered this area. Schwoebel and Coslett (2005) found that a deficit in the topological map of the body (defined by the Authors as "body structural description") was more frequent after left, but not right, temporal damage. Finding a prominent role of the left hemisphere in their study could be due to the presence of a semantic component in the task used to assess body structural description. The middle temporal gyrus is part of the default mode network (Yeo et al., 2011) and has been showed to be more active when individuals are engaged in internally focused tasks (Buckner, Andrews-Hanna, \& Schacter, 2008). The present results tentatively 
suggest the involvement of a specific node of the default mode network - namely the middle temporal gyrus - in the disruption of topological map of the body.

Finding that the anterior insula and the parietal lobe are involved in topological map of the body is in line with results by Hilti et al. (2013), who showed modifications of the cortical thickness in these areas in patients affected by xenomelia, a disorder associated with the desire of amputation of healthy limbs, in absence of any brain damage.

Generally, the present results strongly support the involvement of the right hemisphere in processing spatial knowledge about the body. On one hand, worse performances in a test assessing the topological map of the body were correlated only with lesions in the right hemisphere; on the other hand, only right brain damage patients performed significantly worse than healthy individuals in this task. Nevertheless, it must be considered that the need for enrolling patients without overt language disturbances could have resulted in the exclusion from the study of patients with lesions in areas critical for body representation, namely the left parietal lobe, which is also usually associated with aphasic disorders. Indeed, this area, which lesion is very frequent, has been repeatedly found to be involved in the topological map of the body (CorradiDell'Aqua et al., 2008, 2009; Ehrsson et al., 2005; Felician et al., 2004).

The hodological symptom mapping revealed that the disconnection of the right Fronto-marginal tract predicts FBE's performances. The fronto-marginal tract connects the medial and lateral regions of the frontal pole (Rojkova et al., 2016). In the present study, damage to regions linked by the Fronto-marginal tract, namely the orbitomedial prefrontal cortex, has been associated with FBE's worse performances. Northoff and Bermpohl (2004), in reviewing the role of the cortical midline structures in the constitution of the self, found that these regions are involved in representing self-referential stimuli. They also suggested that orbitomedial prefrontal cortex is a convergent area builds up a multimodal representation of the stimuli which allows to label them as self-referential, by binding different pieces of information about the body (e.g., temperature, proprioception but also auditory and visual input). The involvement of the fronto-marginal tracts in the worse performances on FBE fits well with the idea that the topological map of the body also relies on the actual somatosensory and interoceptive information to be formed.

In sum, the performance of patients affected by personal neglect can be attributed to an alteration in a specific body representation, namely the topological body representation, which is build up basing on the external and internal information that comes from the body and are constantly updated and integrated. Current results shed precious light on the relation between the brain and the body processing and provide new insights on personal neglect features. This knowledge could be also relevant in developing rehabilitation programs rooted in a clear understanding of the cognitive processes compromised in this disorder.

\section{References}

Anema, H. A., Kessels, R. P., de Haan, E. H., Kappelle, L. J., Leijten, F. S., van Zandvoort, M. J., \& Dijkerman, H. C. (2008). Differences in finger localisation performance of patients with finger agnosia. NeuroReport: For Rapid Communication of Neuroscience Research, 19, 1429-1433. http://dx.doi.org/10.1097/WNR.0b013e32830e017b
Arzy, S., Thut, G., Mohr, C., Michel, C. M., \& Blanke, O. (2006). Neural basis of embodiment: Distinct contributions of temporoparietal junction and extrastriate body area. The Journal of Neuroscience, 26, 80748081. http://dx.doi.org/10.1523/JNEUROSCI.0745-06.2006

Baas, U., de Haan, B., Grässli, T., Karnath, H. O., Mueri, R., Perrig, W. J., . . . Gutbrod, K. (2011). Personal neglect-a disorder of body representation? Neuropsychologia, 49, 898-905. http://dx.doi.org/10.1016/j neuropsychologia.2011.01.043

Basso, A., Capitani, E., \& Laiacona, M. (1987). Raven's coloured progressive matrices: Normative values on 305 adult normal controls. Functional Neurology, 2, 189-194.

Bates, E., Wilson, S. M., Saygin, A. P., Dick, F., Sereno, M. I., Knight, R. T., \& Dronkers, N. F. (2003). Voxel-based lesion-symptom mapping. Nature Neuroscience, 6, 448-450. http://dx.doi.org/10.1038/nn1050

Berlucchi, G., \& Aglioti, S. M. (2010). The body in the brain revisited. Experimental Brain Research, 200, 25-35. http://dx.doi.org/10.1007/ s00221-009-1970-7

Boccia, M., Piccardi, L., Palermo, L., Nemmi, F., Sulpizio, V., Galati, G., \& Guariglia, C. (2015). A penny for your thoughts! patterns of fMRI activity reveal the content and the spatial topography of visual mental images. Human Brain Mapping, 36, 945-958. http://dx.doi.org/10.1002/ hbm. 22678

Brazzelli, M., Capitani, E., Della Sala, S., Spinnler, H., \& Zuffi, M. (1994). A neuropsychological instrument adding to the description of patients with suspected cortical dementia: The Milan Overall Dementia Assessment. Journal of Neurology, Neurosurgery, \& Psychiatry, 57, 15101517.

Brett, M., Leff, A. P., Rorden, C., \& Ashburner, J. (2001). Spatial normalization of brain images with focal lesions using cost function masking. NeuroImage, 14, 486-500. http://dx.doi.org/10.1006/nimg.2001 .0845

Buckner, R. L., Andrews-Hanna, J. R., \& Schacter, D. L. (2008). The brain's default network: Anatomy, function, and relevance to disease. Annals of the New York Academy of Sciences, 1124, 1-38. http://dx.doi .org/10.1196/annals.1440.011

Carruthers, G. (2008). Types of body representation and the sense of embodiment. Consciousness and Cognition: An International Journal, 17, 1302-1316. http://dx.doi.org/10.1016/j.concog.2008.02.001

Ciurli, P., Marangolo, P., \& Basso, A. (1996). Esame del linguaggio II [Examination of language II]. Florence, Italy: O. S. Organizzazioni Speciali.

Committeri, G., Pitzalis, S., Galati, G., Patria, F., Pelle, G., Sabatini, U., . . . Pizzamiglio, L. (2007). Neural bases of personal and extrapersonal neglect in humans. Brain: A Journal of Neurology, 130, 431-441. http://dx.doi.org/10.1093/brain/awl265

Corradi-Dell'Acqua, C., Hesse, M. D., Rumiati, R. I., \& Fink, G. R. (2008). Where is a nose with respect to a foot? The left posterior parietal cortex processes spatial relationships among body parts. Cerebral Cortex, 18, 2879-2890. http://dx.doi.org/10.1093/cercor/bhn046

Corradi-Dell'Acqua, C., Tomasino, B., \& Fink, G. R. (2009). What is the position of an arm relative to the body? Neural correlates of body schema and body structural description. The Journal of Neuroscience, 29, 4162-4171. http://dx.doi.org/10.1523/JNEUROSCI.4861-08.2009

Coslett, H. B. (1998). Evidence for a disturbance of the body schema in neglect. Brain and Cognition, 37, 527-544. http://dx.doi.org/10.1006/ brcg.1998.1011

Costantini, M., \& Haggard, P. (2007). The rubber hand illusion: Sensitivity and reference frame for body ownership. Consciousness and Cognition: An International Journal, 16, 229-240. http://dx.doi.org/10.1016/j .concog.2007.01.001

Craig, A. D. (2003). Interoception: The sense of the physiological condition of the body. Current Opinion in Neurobiology, 13, 500-505. http://dx.doi.org/10.1016/S0959-4388(03)00090-4 
Daurat-Hmeljiak, C., Stambak, M., \& Berges, J. (1978). Il test dello schema corporeo. Una prova di conoscenza e costruzione dell'immagine del corpo [The body schema test. A test of knowledge and construction of body image]. Firenze, Italy: Organizzazioni Speciali.

Denes, G. (1989). Disorders of body awareness and body knowledge. In F. Boller \& J. Grafman (Eds.), Handbook of neuropsychology (pp. 207227). Amsterdam, the Netherlands: Elsevier.

Dijkerman, H. C., \& de Haan, E. H. (2007). Somatosensory processes subserving perception and action. Behavioral and Brain Sciences, 30, 189-201. http://dx.doi.org/10.1017/S0140525X07001392

Di Vita, A., Boccia, M., Palermo, L., \& Guariglia, C. (2016). To move or not to move, that is the question! Body schema and non-action oriented body representations: An fMRI meta-analytic study. Neuroscience and Biobehavioral Reviews, 68, 37-46. http://dx.doi.org/10.1016/j .neubiorev.2016.05.005

Di Vita, A., Palermo, L., Piccardi, L., Di Tella, J., Propato, F., \& Guariglia, C. (2017). Body representation alterations in personal but not in extrapersonal neglect patients. Applied Neuropsychology: Adult, 24, 308-317. http://dx.doi.org/10.1080/23279095.2016.1174866

Di Vita, A., Palermo, L., Piccardi, L., \& Guariglia, C. (2015). Peculiar body representation alterations in hemineglect: A case report. Neurocase, 21, 697-706. http://dx.doi.org/10.1080/13554794.2014.974620

Ehrsson, H. H., Kito, T., Sadato, N., Passingham, R. E., \& Naito, E. (2005). Neural substrate of body size: Illusory feeling of shrinking of the waist. PLoS Biology, 3(12), e412. http://dx.doi.org/10.1371/journal.pbio .0030412

Felician, O., Romaiguère, P., Anton, J. L., Nazarian, B., Roth, M., Poncet, M., \& Roll, J. P. (2004). The role of human left superior parietal lobule in body part localization. Annals of Neurology, 55, 749-751. http://dx .doi.org/10.1002/ana.20109

Galati, G., Committeri, G., Sanes, J. N., \& Pizzamiglio, L. (2001). Spatial coding of visual and somatic sensory information in body-centred coordinates. European Journal of Neuroscience, 14, 737-746. http://dx.doi .org/10.1046/j.0953-816x.2001.01674.x

Grossi, D., Di Vita, A., Palermo, L., Sabatini, U., Trojano, L., \& Guariglia, C. (2014). The brain network for self-feeling: A symptom-lesion mapping study. Neuropsychologia, 63, 92-98. http://dx.doi.org/10.1016/j .neuropsychologia.2014.08.004

Guariglia, C., \& Antonucci, G. (1992). Personal and extrapersonal space: A case of neglect dissociation. Neuropsychologia, 30, 1001-1009. http:// dx.doi.org/10.1016/0028-3932(92)90051-M

Guariglia, C., Piccardi, L., Puglisi Allegra, M. C., \& Traballesi, M. (2002). Is autotopoagnosia real? EC says yes. A case study. Neuropsychologia, 40, 1744-1749. http://dx.doi.org/10.1016/S0028-3932(02)00013-1

Head, H. (1920). Studies in neurology (Vol. 2). London, UK: Oxford University Press.

Hilti, L. M., Hänggi, J., Vitacco, D. A., Kraemer, B., Palla, A., Luechinger, R., . . Brugger, P. (2013). The desire for healthy limb amputation: Structural brain correlates and clinical features of xenomelia. Brain: A Journal of Neurology, 136, 318-329. http://dx.doi.org/10.1093/brain/ aws 316

Hodzic, A., Kaas, A., Muckli, L., Stirn, A., \& Singer, W. (2009). Distinct cortical networks for the detection and identification of human body. NeuroImage, 45, 1264-1271. http://dx.doi.org/10.1016/j.neuroimage .2009 .01 .027

Knoblich, G., Thorton, I., Grosjean, M., \& Shiffrar, M. (2006). Human body perception from the inside out (pp. 3-8). New York, NY: Oxford University Press.

Le Clec'H, G., Dehaene, S., Cohen, L., Mehler, J., Dupoux, E., Poline, J. B., . . . Le Bihan, D. (2000). Distinct cortical areas for names of numbers and body parts independent of language and input modality. NeuroImage, 12, 381-391. http://dx.doi.org/10.1006/nimg.2000.0627
Longo, M. R. (2016). Types of body representation. In Y. Coello \& M. H. Fischer (Eds.), Foundations of embodied cognition: Vol. 1. Perceptual and Emotional Embodiment (pp. 117-134). London, UK: Routledge.

Longo, M. R., Azañón, E., \& Haggard, P. (2010). More than skin deep: Body representation beyond primary somatosensory cortex. Neuropsychologia, 48, 655-668. http://dx.doi.org/10.1016/j.neuropsychologia 2009.08.022

Magni, E., Binetti, G., Bianchetti, A., Rozzini, R., \& Trabucchi, M. (1996). Mini-Mental State Examination: A normative study in Italian elderly population. European Journal of Neurology, 3, 198-202. http://dx.doi .org/10.1111/j.1468-1331.1996.tb00423.x

Miceli, G., Laudanna, A., Burani, C., \& Capasso, R. (1994). Batteria per l'analisi dei deficit afasici (BADA) [Battery to analyze aphasic deficits (BADA)]. Rome, Italy: Universita' Cattolica del Sacro Cuore.

Northoff, G., \& Bermpohl, F. (2004). Cortical midline structures and the self. Trends in Cognitive Sciences, 8, 102-107. http://dx.doi.org/10 $.1016 /$ j.tics.2004.01.004

Palermo, L., Di Vita, A., Piccardi, L., Traballesi, M., \& Guariglia, C. (2014). Bottom-up and top-down processes in body representation: A study of brain-damaged and amputee patients. Neuropsychology, 28 , 772-781. http://dx.doi.org/10.1037/neu0000086

Pizzamiglio, L., Judica, A., Razzano, C., \& Zoccolotti, P. (1989). Toward a comprehensive diagnosis of visual spatial disorders in unilateral brain damaged patients. Evaluación Psicológica, 5, 199-218.

Raven, J. C. (1938). Standard Progressive Matrices: Sets A, B, C, D and EHK. London, UK: Lewis.

Rojkova, K., Volle, E., Urbanski, M., Humbert, F., Dell'Acqua, F., \& Thiebaut de Schotten, M. (2016). Atlasing the frontal lobe connections and their variability due to age and education: A spherical deconvolution tractography study. Brain Structure \& Function, 221, 1751-1766. http:// dx.doi.org/10.1007/s00429-015-1001-3

Rorden, C., Karnath, H.-O., \& Bonilha, L. (2007). Improving lesionsymptom mapping. Journal of Cognitive Neuroscience, 19, 1081-1088. http://dx.doi.org/10.1162/jocn.2007.19.7.1081

Rusconi, E., Tamè, L., Furlan, M., Haggard, P., Demarchi, G., Adriani, M., . . . Schwarzbach, J. (2014). Neural correlates of finger gnosis. The Journal of Neuroscience, 34, 9012-9023. http://dx.doi.org/10.1523/ JNEUROSCI.3119-13.2014

Schwoebel, J., \& Coslett, H. B. (2005). Evidence for multiple, distinct representations of the human body. Journal of Cognitive Neuroscience, 17, 543-553. http://dx.doi.org/10.1162/0898929053467587

Sirigu, A., Grafman, J., Bressler, K., \& Sunderland, T. (1991). Multiple representations contribute to body knowledge processing. Evidence from a case of autotopagnosia. Brain: A Journal of Neurology, 114(Part 1B), 629-642. http://dx.doi.org/10.1093/brain/114.1.629

Spinnler, H., \& Tognoni, G. (1987). Standardizzazione e taratura italiana di tests neuropsicologici [Italian normative values and standardization of neuropsychological tests]. Italian Journal of Neurological Sciences, 6(Suppl. 8), 1-20.

Spitoni, G. F., Galati, G., Antonucci, G., Haggard, P., \& Pizzamiglio, L. (2010). Two forms of touch perception in the human brain. Experimental Brain Research, 207(3-4), 185-195. http://dx.doi.org/10.1007/s00221010-2446-5

Spitoni, G. F., Pireddu, G., Cimmino, R. L., Galati, G., Priori, A., Lavidor, M., . . . Pizzamiglio, L. (2013). Right but not left angular gyrus modulates the metric component of the mental body representation: A tDCS study. Experimental Brain Research, 228, 63-72. http://dx.doi .org/10.1007/s00221-013-3538-9

Tamè, L., Dransfield, E., Quettier, T., \& Longo, M. R. (2017). Finger posture modulates structural body representations. Scientific Reports, 7, 43019. http://dx.doi.org/10.1038/srep43019

Tessari, A., Ottoboni, G., Baroni, G., Symes, E., \& Nicoletti, R. (2012). Is access to the body structural description sensitive to a body part's significance for action and cognition? A study of the sidedness effect 
using feet. Experimental Brain Research, 218, 515-525. http://dx.doi .org/10.1007/s00221-012-3045-4

Thiebaut de Schotten, M., Tomaiuolo, F., Aiello, M., Merola, S., Silvetti, M., Lecce, F., . . Doricchi, F. (2014). Damage to white matter pathways in subacute and chronic spatial neglect: A group study and 2 single-case studies with complete virtual "In Vivo" tractography dissection. Cerebral Cortex, 24, 691-706. http://dx.doi.org/10.1093/cercor/bhs351

Tsakiris, M., Costantini, M., \& Haggard, P. (2008). The role of the right temporo-parietal junction in maintaining a coherent sense of one's body. Neuropsychologia, 46, 3014-3018. http://dx.doi.org/10.1016/j .neuropsychologia.2008.06.004

Tsakiris, M., \& Haggard, P. (2005). The rubber hand illusion revisited: Visuotactile integration and self-attribution. Journal of Experimental Psychology: Human Perception and Performance, 31, 80-91. http://dx .doi.org/10.1037/0096-1523.31.1.80

Urgesi, C., Calvo-Merino, B., Haggard, P., \& Aglioti, S. M. (2007). Transcranial magnetic stimulation reveals two cortical pathways for visual body processing. The Journal of Neuroscience, 27, 8023-8030. http://dx.doi.org/10.1523/JNEUROSCI.0789-07.2007

Yeo, B. T., Krienen, F. M., Sepulcre, J., Sabuncu, M. R., Lashkari, D., Hollinshead, M., . . . Buckner, R. L. (2011). The organization of the human cerebral cortex estimated by intrinsic functional connectivity. Journal of Neurophysiology, 106, 1125-1165. http://dx.doi.org/10.1152/ jn.00338.2011

Zoccolotti, P., Antonucci, G., \& Judica, A. (1992). Psychometric characteristics of two semistructured scales for the functional evaluation of hemi-inattention in extrapersonal and personal space. Neuropsychological Rehabilitation, 2, 179-191. http://dx.doi.org/10.1080/ 09602019208401407

Received June 3, 2018

Revision received November 9, 2018 Accepted November 18, 2018 